\title{
molecules
}

ISSN 1420-3049

(C) 2007 by MDPI

www.mdpi.org/molecules

Full Paper

\section{Diastereoselective Spiroannulation of Phenolic Substrates: Advances Towards the Asymmetric Formation of the Manumycin $\mathbf{m}-\mathrm{C}_{7} \mathbf{N}$ Core Skeleton}

\author{
Guy L. Plourde ${ }^{*}$, Randy R. Spaetzel, Jolene S. Kwasnitza and Thomas W. Scully \\ University of Northern British Columbia, Department of Chemistry, 3333 University Way, Prince \\ George, British Columbia, Canada, V2N 4Z9; Tel: +1-250-960-6694, Fax: +1-250-960-5845 \\ * Author to whom correspondence should be addressed; E-mail: plourde@unbc.ca
}

Received: 7 September 2007; in revised form: 24 September 2007 / Accepted: 24 September 2007 / Published: 25 September 2007

\begin{abstract}
The asymmetric syntheses of two new spirolactones prepared in optically pure form from $L$-3-nitrotyrosine are described. The key step, an oxidative spiroannulation, was carried out on the optically active phenols 11a and $\mathbf{1 1 b}$ and afforded the new spirolactones $\mathbf{5 a}$ and $\mathbf{5 b}$ in $85 \%$ and $83 \%$ yields, respectively, as mixtures (3:1 dr) of diastereomers. The major diastereomers from these mixtures could be isolated in optically pure form by trituration using acetone-hexanes as the solvent. Thus, the optically active spirolactones $(+)-5 \mathbf{a}\left(+92.8^{\circ}, \mathrm{c}=0.125\right.$ acetone $)$ and $(+)-5 \mathbf{b}\left(+112.0^{\circ}, \mathrm{c}=0.125\right.$ acetone) were obtained after four synthetic steps from $L-3$-nitrotyrosine in $41 \%$ and $43 \%$ yield, respectively.
\end{abstract}

Keywords: Spiroannulation, oxidation, phenol, diastereoselective, asymmetric, Manumycins, Aranorosins, Gymnastatins.

\section{Introduction}

Our previous investigations of the diastereoselective spiroannulation of simple phenols have shown that it is possible to obtain facial selectivity in these reactions [1-4]. While only modest diastereoselectivities ( 4:1 ratio) have been obtained to date, these results suggested that this method could be used in the design of diastereoselective syntheses of natural products. More accurately, we 
felt that spirocompounds of general structure 1 (Figure 1) could be used in the synthesis of the core carbon skeleton of natural products (or analogs) from three families: Gymnastatins (2), Aranorosins (3) and Manumycins (4). A representative example for each family is shown in Figure 1 (structures 24).

Figure 1.<smiles>[R1]C1=CC2(C=CC1=O)CC([R2])C(=O)O2</smiles>

1

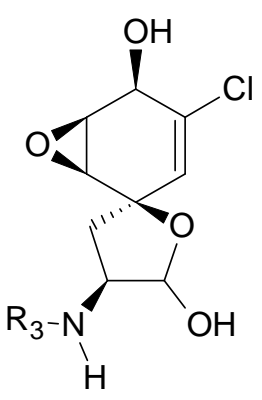

2 Gymnastatin E

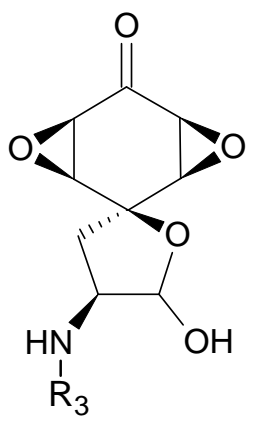

3 Aranorosin<smiles>[R4]NC1=C[C@@](C)(O)[C@H]2O[C@H]2C1=O</smiles>

$\mathrm{OH}$

4 Nisamycin<smiles>[R5]=CC=CC(C)=C[C@@H](C)CCCCCC</smiles><smiles>[R]=CC=CC=CC1CCCC1</smiles>

Assuming that the spirocompound $\mathbf{1}$ bears the proper functional groups at positions $\mathrm{R}_{1}$ and $\mathrm{R}_{2}$, it appears to be a good starting point for the syntheses of these natural products. While there are already numerous syntheses of members of the Manumycins [5-13], Aranorosins [14-16] and Gymnastatins [17], this new approach could be advantageous since it may allow for the synthesis of more than one of these structures from the same starting material. We have investigated the asymmetric synthesis of spirolactones 5 (Figure 2) bearing substituents that would mimic the general functionality found in most members of the Manumycin family (cf. structure 4). We now wish to report our preliminary results toward the asymmetric synthesis of compound 5, which we hope will become a precursor for the synthesis of analogs of the Manumycin family of compounds.

\section{Results and Discussion}

The diastereoselective formation of spirolactones $\mathbf{5 a}$ and $\mathbf{5 b}$ is described in Scheme 1 . Commercially available $L$-3-nitrotyrosine $\mathbf{8}$ was chosen as the starting material for two reasons: (1) it provides the means to generate the amide function found in the Manumycins via its nitro function (see Figure 1), and (2), it bears an optically pure chiral center on the side chain para to the hydroxyl, as shown in phenols 11a/11b. Our previous studies of the diastereoselective spiroannulation of simple phenols have shown that for side chains similar to the one found in 11, it was possible to induce face selectivity and obtain a 4:1 diastereomeric ratio of spiroethers 6a-c and 7, which are analogous in structure to 5/12, as shown in Figure $2[1,2,4]$. We hoped that in the formation of spirolactones 5/12, a 
similar or greater ratio of diastereomers could be generated since the chiral center in the side chain of $\mathbf{1 1}$ is located at a position similar to that of the chiral center used in our previous studies.

\section{Figure 2.}<smiles>[R]C(=O)NC1=CC2(C=CC1=O)CC([AlH2])C(=O)O2</smiles><smiles>[R]C1CCC2(C=CC(=O)C(OC)=C2)O1</smiles>

$$
\begin{array}{rl}
\text { 5a } \mathrm{R}=\mathrm{CH}_{3} & \mathbf{6 a} \mathrm{R}=\text { methyl } \\
\text { 5b } \mathrm{R}=\mathrm{C}_{6} \mathrm{H}_{5} & \mathbf{6 b} \mathrm{R}=\text { isopropyl } \\
& \mathbf{6 c} \mathrm{R}=\text { tert-butyl }
\end{array}
$$<smiles>COC1=CC(=O)C=CC12CCC(C(C)(C)C)O2</smiles>

7

\section{Scheme 1.}<smiles>C[13CH][13CH]N[C@@H](Cc1ccc(O)c([N+](=O)[O-])c1)[C@H](C)C(=O)O</smiles>

8

10<smiles>[R]C(=O)NC1=CC2(C=CC1=O)C[C@@H](N)C(=O)O2</smiles><smiles>[R]C(=O)NC1=CC2(C=CC1=O)C[C@@H](N[I+])C(=O)O2</smiles><smiles>CCCCCCCC</smiles><smiles>[R]C(=O)Nc1cc(C[C@H](NS)C(=O)O)ccc1O</smiles>

(+)-5a R= $\mathrm{CH}_{3}$ 12a $\mathrm{R}=\mathrm{CH}_{3}$ 11a $\mathrm{R}=\mathrm{CH}_{3}$ (+)-5b R= $\mathrm{C}_{6} \mathrm{H}_{5}$ 12b $\mathrm{R}=\mathrm{C}_{6} \mathrm{H}_{5}$ 11b $\mathrm{R}=\mathrm{C}_{6} \mathrm{H}_{5}$

(a) 1) TsCl, THF, $1 \mathrm{M} \mathrm{NaOH}$ 2) $1 \mathrm{M} \mathrm{KOH}, \mathrm{EtOH}, 80-85^{\circ} \mathrm{C}$; (b) $\mathrm{H}_{2}, 10 \% \mathrm{Pd} / \mathrm{C}$, THF; (c) $\mathrm{CH}_{3} \mathrm{COCl}$ or PhCOCl, THF, rt; (d) PIFA, acetone, $0^{\circ} \mathrm{C}$ 
Treatment of $\mathbf{8}$ with $p$-toluenesulfonyl chloride in tetrahydrofuran afforded a mixture of products consisting of the mono- $N$-protected phenol 9 and a product that we identified by ${ }^{1} \mathrm{H}-\mathrm{NMR}$ as a diprotected product, ie. both the amino and hydroxyl functions in $\mathbf{8}$ had reacted with the sulfonyl chloride. Hydrolysis of the resulting mixture with $1 \mathrm{M} \mathrm{KOH}$ at $80^{\circ} \mathrm{C}$ afforded only 9 in $86 \%$ yield as a yellow solid after recrystallization from benzene. Since the sulfonate ester is easier to hydrolyze than the sulfonamide function, we were able to avoid the extra steps that protection/deprotection of the phenolic hydroxyl would have necessitated. Hydrogenation of the nitro function in $\mathbf{9}$ afforded the aniline derivative $\mathbf{1 0}$ as a white solid. The crude yield for $\mathbf{1 0}$ appeared to be quantitative (based on mass recovery), however, every attempt to purify this compound by column chromatography or recrystallization failed. In these cases, we obtained low yields (40-60\%), but more importantly, these purification attempts at $\mathbf{1 0}$ generated a product that was less pure (based on ${ }^{1} \mathrm{H}-\mathrm{NMR}$ ) than the crude reaction product itself. Consequently, compound $\mathbf{1 0}$ was used without purification in the subsequent reaction and the identity of this compound was based primarily on its ${ }^{1} \mathrm{H}-\mathrm{NMR}$ spectrum.

Treatment of $\mathbf{1 0}$ with either acetyl chloride or benzoyl chloride afforded 11a and 11b in 84\% and $87 \%$ yields, respectively, after purification by column chromatography. The spiroannulation of 11a and 11b was carried out with phenyliodine(III) bistrifluoroacetate (PIFA) in acetone at $0^{\circ} \mathrm{C}$. In the reaction of 11a, a mixture of diastereomers $\mathbf{5 a / 1 2 a}$ was obtained in a 3:1 diastereomeric ratio. The ratio of major/minor diastereomers formed in the spiroannulation was determined by integration for the signals of $\mathrm{H}-9$ (two doublets centered at $6.37 \mathrm{ppm}$ ) in the ${ }^{1} \mathrm{H}-\mathrm{NMR}$ spectrum of the crude diastereomeric mixture. In the reaction of $\mathbf{1 1 b}$, the two doublets for compounds $\mathbf{5 b} \mathbf{b} \mathbf{1 2} \mathbf{b}$ (centered at $6.40 \mathrm{ppm}$ ) were overlapping slightly, making the determination of the diastereomeric ratio less accurate. However, it was obvious from the ${ }^{1} \mathrm{H}-\mathrm{NMR}$ of the crude reaction mixture that one stereoisomer was produced in a larger amount than the other one. We estimated that for $\mathbf{5 b} / \mathbf{1 2} \mathbf{b}$ this ratio was between 3:1 and 4:1. Attempts to separate the major and minor stereoisomers from these mixtures met with limited success. Our first attempt was carried out by column chromatography of the 5a/12a mixture using 50\% ethyl acetate-hexanes as eluant. We were able to separate the major diastereomer 5 a from the mixture under these conditions but this fraction represented only $38 \%$ of the total isolated mass (or 32\% yield from 11a). We were not successful in isolating the minor diastereomer from this mixture. We later found that both $\mathbf{5 a}$ and $\mathbf{5 b}$ could be isolated via trituration using an acetone/hexanes mixture. In both cases, we were able to isolate the major diastereomers $(+)$ 5a and (+)-5b from the crude reaction mixtures. The isolated mass obtained for each compound represents a $57 \%$ yield from the corresponding optically active phenols $\mathbf{1 1 a} / \mathbf{1 1 b}$, or a $41 \%$ total yield for $(+)-5 \mathbf{a}$ and $43 \%$ for $(+)-5 \mathbf{b}$. Finally, while we were able to isolate the major diastereomer in these reactions, we have not yet identified the configuration of the newly formed chiral spirocenter in $\mathbf{5 a}$ or 5b. As a result, in Scheme 1 we have not drawn the stereo bonds of the spirocenters in the structures of $\mathbf{5 a} / \mathbf{b}$ or $\mathbf{1 2 a} / \mathbf{b}$. However, both major diastereomers gave a positive optical rotation and are labeled accordingly in Scheme 1.

\section{Conclusions}

We have successfully prepared optically active spirocompounds (+)-5a and (+)-5b. While the diastereomeric ratio observed in the reaction leading to these compounds is modest at best, it suggests that the method could be useful in the asymmetric synthesis of natural products since we were able to 
obtain the major diastereomers in optically pure forms. We have now begun an investigation of the use of these compounds in the synthesis of the core skeleton of the Manumycins. Furthermore, we are attempting to identify the configuration of the new chiral spirocenters in (+)-5a and (+)-5b as well as ways to enhance the diastereomeric ratios observed in these reactions.

\section{Acknowledgements}

We acknowledge the financial contribution of the University of Northern British Columbia in support of this work.

\section{Experimental}

\section{General}

Melting points were determined on a hot stage instrument and are uncorrected. Infrared spectra were recorded on a Perkin Elmer System 2000 FTIR either as $\mathrm{KBr}$ pellets or neat. ${ }^{1} \mathrm{H}$ - and ${ }^{13} \mathrm{C}-\mathrm{NMR}$ spectra were recorded on a Bruker AMX300 spectrometer operating at $300 \mathrm{MHz}\left({ }^{1} \mathrm{H}\right)$ and $75.4 \mathrm{MHz}$ $\left({ }^{13} \mathrm{C}\right)$. Chemical shifts are expressed in ppm using TMS $\left({ }^{1} \mathrm{H}\right)$ or the residual solvent signal $\left({ }^{13} \mathrm{C}\right)$ as internal standards. Coupling constants $(J)$ are expressed in Hz. Mass spectra were recorded on a Hewlett Packard 5898B spectrometer. Optical rotations were recorded on a Rudolph Research Autopol III Automatic Polarimeter.

\section{(2S)-3-(4-Hydroxy-3-nitrophenyl)-2-\{[(4-methylphenyl)sulfonyl]amino\} propanoic acid [(-)-9]}

A solution of $p$-toluenesulfonyl chloride (7.012 g, $36.9 \mathrm{mmol}, 8.1$ eq.) in tetrahydrofuran (150 mL) was added in three portions (5-10 minutes apart) to a solution of 3-nitro- $L$-tyrosine (1.029 g, 4.55 $\mathrm{mmol})$ in $1 \mathrm{M} \mathrm{NaOH}(100 \mathrm{~mL})$. The resulting orange solution was stirred vigorously at room temperature. After 25-30 minutes the solution became yellow, indicating an acidic environment ( $\mathrm{pH} \sim$ 3), therefore more $1 \mathrm{M} \mathrm{NaOH}$ ( $25 \mathrm{~mL}$ ) was added. The resulting orange solution was stirred overnight (14-16 hours). The reaction mixture was acidified with $10 \% \mathrm{HCl}(\mathrm{pH} 2)$ and extracted with dichloromethane $(3 \times 50 \mathrm{~mL})$. The organic fractions were combined, dried $\left(\mathrm{MgSO}_{4}\right)$ and the solvent evaporated to afford a yellow solid. The crude yellow product was dissolved in ethanol (100 $\mathrm{mL})$ and $1 \mathrm{M} \mathrm{KOH}(50 \mathrm{~mL})$ was added. The solution was stirred at $80-85^{\circ} \mathrm{C}$ overnight $(12-14$ hours $)$. The resulting reaction mixture was cooled and acidified with $10 \% \mathrm{HCl}(\mathrm{pH} 2)$, concentrated and extracted with dichloromethane (2 x $150 \mathrm{~mL})$. The organic fractions were combined, dried $\left(\mathrm{MgSO}_{4}\right)$, and the solvent was evaporated leaving a yellow solid. Recrystallization from benzene afforded a yellow solid (1.485 g, 86 \%); mp: $137-138^{\circ} \mathrm{C}$; [ $\left.\alpha\right]_{\mathrm{D}}:-10.4^{\circ}$ (c: 0.125, acetone); IR (KBr, cm ${ }^{-1}$ ): $3291(\mathrm{OH}), 1734$ (CO); ${ }^{1} \mathrm{H}-\mathrm{NMR}\left(\mathrm{CDCl}_{3}\right) \delta: 2.40$ (s, 3H, H-7'), 2.91 (m, 1H, H-3a), 3.15 (m, 1H, H-3b), 3.74 (broad s, $1 \mathrm{H}, \mathrm{OH}), 4.16$ (m, 1H, H-2), 5.42 (d, 1H, J=8.5, N-H), 7.01 (d, 1H, J=8.6, H-8), 7.20 (d, 2H, J=8.3, H2', H-6'), 7.38 (dd, 1H, J=2.2, 8.6, H-9), 7.56 (d, 2H, J=8.3, H-3', H-5'), 7.74 (d, 1H, J=2.2, H-5), 10.46 (broad s, $\left.1 \mathrm{H}, \mathrm{CO}_{2} \mathrm{H}\right)$; ${ }^{13} \mathrm{C}-\mathrm{NMR}\left(\mathrm{CDCl}_{3}\right) \delta:$ 21.7, 37.7, 56.6, 120.4, 125.6, 127.2, 127.7, 129.9, 133.3, 136.4, 139.2, 144.4, 154.5, 174.7; MS m/z (rel. \%): 380 (32, M+), 293 (22), 258 (25), 228 (43), 209 (31), 178 (26), 155 (98), 135 (92), 117 (32), 106 (52), 91 (100), 77 (42), 65 (83), 51 (49). 
(2S)-3-(3-Amino-4-hydroxylphenyl)-2-\{[(4-methylphenyl)sulfonyl]amino\} propanoic acid [(+)-10]

To a solution of (-)-9 (925 mg, $2.43 \mathrm{mmol})$ in tetrahydrofuran $(100 \mathrm{~mL})$ was added 10\% Pd/C (250 mg). The resulting mixture was placed in a hydrogenator, flushed (five times) with $\mathrm{H}_{2}$ and left to agitate under pressure (32 psi) for 16 hrs. The reaction mixture was vented, filtered through Celite ${ }^{\circledR}$ and solvent evaporated to afford a whitish solid. Initial attempts to purify by recrystallization or column chromatography failed and characterization of this product was carried out using the crude product; mp: $112-113^{\circ} \mathrm{C}$; $[\alpha]_{\mathrm{D}}:+10.2^{\circ}$ (c: $0.125, \mathrm{CH}_{3} \mathrm{CN}$ ); ${ }^{1} \mathrm{H}-\mathrm{NMR}\left(\mathrm{D}_{2} \mathrm{O}+\mathrm{Na}_{2} \mathrm{CO}_{3}\right) \delta: 2.35$ (s, 3H, H7'), 2.45 (m, 1H, H-3a), 2.78 (m, 1H, H-3b), 3.59 (m, 1H, H-2), 6.33 (m, 3H, H-5, H-8, H-9), 7.22 (d, 2H, J=8.6, H-3', H-5'), 7.39 (d, 2H, J=8.3, H-2', H-6'); MS m/z (rel. \%): 350 (5, M+'), 179 (4), 155 (5), 122 (100), 91 (16), 77 (8), 65 (11).

(2S)-3-[3(Acetylamino)-4-hydroxyphenyl]-2-\{[(4-methylphenyl)sulfonyl]amino\} propanoic acid [(-)-11a]

To a solution of $(+)-10$ (188 mg, $0.54 \mathrm{mmol})$ in tetrahydrofuran $(10 \mathrm{~mL})$ was added acetyl chloride (79 mg, $1.02 \mathrm{mmol}, 1.9$ eq.) and the solution was stirred at room temperature overnight (19 hours). The reaction mixture was diluted with $\mathrm{CH}_{2} \mathrm{Cl}_{2}(50 \mathrm{~mL})$, washed with brine $(15 \mathrm{~mL})$, dried $\left(\mathrm{MgSO}_{4}\right)$ and evaporated. Chromatography on silica gel using 20\% methanol-chloroform as eluant afforded a beige solid (176 mg, 84\%); mp: $153-154^{\circ} \mathrm{C}$; $[\alpha]_{\mathrm{D}}:-7.3^{\circ}$ (c: 0.137 , acetone); IR (KBr, $\mathrm{cm}^{-1}$ ): 3416 (NH), 3257 (NH), 1777 (CO), 1721 (CO); ${ }^{1} \mathrm{H}-\mathrm{NMR}$ (acetone-d ${ }_{6}$ ) $\delta: 2.20$ (s, 3H, H-2"), 2.38 (s, 3H, H7'), 2.83 (m, 1H, H-3a), 2.93 (m, 1H, H-3b), 4.04 (m, 1H, H-2), 6.64 (d, 1H, NH), 6.70 (d, 1H, J=8.2, H-8), 6.83 (dd, 1H, J=2.1, 8.2, H-9), 7.15 (broad s, 1H, H-5), 7.25 (d, 2H, J=7.9, H-2', H-6'), 7.55 (d, 2H, J=8.3, H-3', H-5'), 9.25 (broad s, $1 \mathrm{H}, \mathrm{CO}_{2} \mathrm{H}$ ); ${ }^{13} \mathrm{C}-\mathrm{NMR}$ (acetone-d $\mathrm{d}_{6}$ ) $\delta: 21.5,23.5,37.7,58.3$, 119.0, 123.0, 127.3, 127.7, 127.9, 128.7, 130.3, 139.1, 143.8, 148.3, 172.6; MS m/z (rel. \%): 392 (1.2, $\mathrm{M}^{+}$), 203 (17), 155 (11), 147 (74), 146 (100), 122 (18), 105 (17), 91 (60), 77 (35), 65 (22), 51 (17).

(2S)-3-[3(Benzoylamino)-4-hydroxyphenyl]-2-\{[(4-methylphenyl)sulfonyl]amino\}propanoic acid [(-)-11b]

To a solution of (+)-10 (568 mg, $1.62 \mathrm{mmol})$ in tetrahydrofuran (40 mL) was added benzoyl chloride (258 mg, $1.84 \mathrm{mmol}, 1.2$ eq.) and the solution was stirred at room temperature overnight (20 hours). The reaction mixture was diluted with $\mathrm{CH}_{2} \mathrm{Cl}_{2}(50 \mathrm{~mL})$, washed with brine $(15 \mathrm{~mL})$, dried $\left(\mathrm{MgSO}_{4}\right)$ and evaporated. Chromatography on silica gel using 20\% methanol-chloroform as eluant afforded a grey solid (640 mg, 87\%); mp: $183-186^{\circ} \mathrm{C}$; $[\alpha]_{\mathrm{D}}:-18.3^{\circ}$ (c: $\left.0.09, \mathrm{CH}_{3} \mathrm{CN}\right)$; IR $\left(\mathrm{KBr}, \mathrm{cm}^{-1}\right)$ :

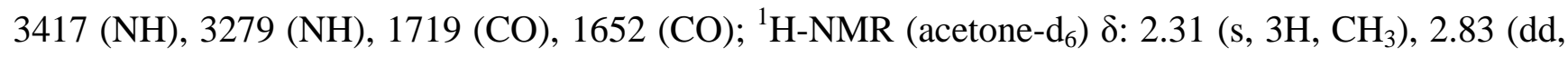
$1 \mathrm{H}, J=5.3,8.3, \mathrm{H}-3 \mathrm{a}$ ), 3.01 (dd, 1H, $J=5.3,13.8, \mathrm{H}-3 \mathrm{~b}$ ), 4.07 (m, 1H, H-2), 6.80 (m, 3H, Ar-H), 7.21 (d, 2H, J=7.9, H-2', H-6'), 7.54 (m, 4H, Ar-H), 8.04 (d, 2H, J=7.9, H-3', H-5'), 9.18 (broad s, 1H, exchangeable with $\mathrm{D}_{2} \mathrm{O}, \mathrm{NH}$ ), 9.45 (broad s, $1 \mathrm{H}$, exchangeable with $\mathrm{D}_{2} \mathrm{O}, \mathrm{OH}$ ); ${ }^{13} \mathrm{C}-\mathrm{NMR}$ (acetone- $\mathrm{d}_{6}$ ) $\delta:$ 21.7, 39.0, 58.6, 118.6, 124.4, 127.5, 127.8, 128.1, 128.7, 129.1, 129.8, 130.4, 133.2, 134.0, 135.1, 139.3, 143.9, 148.6, 167.4, 172.9; MS m/z (rel. \%): $\mathrm{M}^{+}$not observed, 266 (2.3), 209 (22), 208 (37), 155 (9), 105 (100), 91 (74), 77 (92), 65 (27), 51 (40). 
$N$-((3S)-3-\{[(4-Methylphenyl)sulfonyl]amino\}-1-oxaspiro[4.5]deca-6,9-dion-2,8-dien-7-yl) acetamide $[(+)-5 a]$

To a cold $\left(0^{\circ} \mathrm{C}\right)$ solution of $(-)-11 a(602 \mathrm{mg}, 1.54 \mathrm{mmol})$ in acetone $(100 \mathrm{~mL})$ was added PIFA (727 mg, $1.69 \mathrm{mmol}, 1.1$ eq.) in one portion. The orange solution was stirred at $0^{\circ} \mathrm{C}$ for 45 minutes, diluted with EtOAc $(200 \mathrm{~mL})$ and washed with cold water $(2 \times 100 \mathrm{~mL})$. The aqueous portion was extracted with EtOAc $(2 \times 50 \mathrm{~mL})$, the organic fractions combined, dried $\left(\mathrm{MgSO}_{4}\right)$ and evaporated to afford a brown solid (508 mg, 85\%). The crude product was purified by trituration (acetone-hexanes) providing the major diastereomer as a beige solid (340 mg, $57 \%$ ); mp: $173-174^{\circ} \mathrm{C}$; $[\alpha]_{\mathrm{D}}:+92.8^{\circ}$ (c: 0.125, acetone); IR (KBr, cm ${ }^{-1}$ ): 3327 (NH), 1778 (CO), 1654 (CO), 1645 (CO); ${ }^{1} \mathrm{H}-\mathrm{NMR}\left(\mathrm{CD}_{3} \mathrm{CN}\right) \delta$ : 2.16 (s, 3H, H-7'), 2.28 (m, 1H, H-4a), 2.45(s, 3H, H-2"), 2.46 (m, 1H, H-4b), 3.54 (m, 1H, H-3), 6.12 (d, 1H, J=8.0, NH), 6.25 (d, 1H, J=10.0, H-9), 7.06 (dd, 1H, J=3.1, 10.0, H-10), 7.38 (d, 2H, J=8.0, H2', H-6'), 7.52 (d, 1H, J=3.1, H-6), 7.78 (d, 2H, J=8.3, H-3', H-5'), 8.18 (broad s, $1 \mathrm{H}, \mathrm{NH}$ ); ${ }^{13} \mathrm{C}-\mathrm{NMR}$ $\left(\mathrm{CD}_{3} \mathrm{CN}\right) \delta$ : 21.6, 24.7, 40.0, 53.0, 78.4, 124.8, 127.5, 128.0, 130.8, 133.5, 138.8, 145.2, 147.4, 170.9, 173.6; MS m/z (rel. \%): 390 (0.4, M+), 203 (5), 155 (11), 147 (52), 146 (78), 139 (9), 122 (9), 105 (8), 91 (100), 77 (20), 65 (57), 51 (6).

N-((3S)-3-\{[(4-Methylphenyl)sulfonyl]amino\}-1-oxaspiro[4.5]deca-6,9-dion-2,8-dien-7-yl) benzamide $[(+)-5 b]$

To a cold $\left(0^{\circ} \mathrm{C}\right)$ solution of $(-)-11 b(710 \mathrm{mg}, 1.56 \mathrm{mmol})$ in acetone $(100 \mathrm{~mL})$ was added PIFA (677 mg, $1.57 \mathrm{mmol}, 1.0$ eq.) in one portion. The orange solution was stirred at $0^{\circ} \mathrm{C}$ for 45 minutes, diluted with EtOAc $(200 \mathrm{~mL})$ and washed with cold water $(2 \times 100 \mathrm{~mL})$. The aqueous portion was extracted with EtOAc $(2 \times 50 \mathrm{~mL})$, the organic fractions combined, dried $\left(\mathrm{MgSO}_{4}\right)$ and evaporated to afford a brown solid (586 mg, 83\%). The crude product was purified by trituration (acetone-hexanes) providing the major diastereomer as an off-white solid (404 mg, 57\%); mp: $174-175^{\circ} \mathrm{C} ;[\alpha]_{\mathrm{D}}=+112.0^{\circ}$ (c: 0.125, acetone); IR (KBr, cm $\left.{ }^{-1}\right)$ : $3397(\mathrm{NH}), 3290(\mathrm{NH}), 1775$ (CO), 1665 (CO), $1626(\mathrm{CO}) ;{ }^{1} \mathrm{H}-$ NMR $\left(\mathrm{CDCl}_{3}\right) \delta: 2.43$ (s, 3H, H-7'), 2.54 (dd, 1H, J=11.7, 13.6, H-4a), 2.76 (dd, 1H, J=8.7, 13.6, H4b), 4.40 (m, 1H, H-3), 5.66 (d, 1H, J=5.1, NH), 6.39 (d, 1H, J=10.1, H-9), 6.92 (dd, 1H, J=3.1, 10.1, H-10), 7.33 (d, 2H, J=8.0, H-2', H-6'), 7.54 (m, 3H, H-6, H-3', H-5'), 7.83 (m, 5H, aromatic Hs), 8.79 (broad s, $1 \mathrm{H}, \mathrm{NH}) ;{ }^{13} \mathrm{C}-\mathrm{NMR}\left(\mathrm{CDCl}_{3}\right) \delta: 21.8,40.8,52.2,77.4,78.4,124.4,127.4,129.2,129.9$, 130.3, 132.5, 132.8, 133.6, 136.5, 144.6, 145.9, 166.3, 172.6, 179.3; MS m/z (rel. \%): $452\left(0.2, \mathrm{M}^{+}\right)$, 208 (12), 155 (5), 139 (10), 123 (9), 122 (9), 105 (33), 92 (38), 91 (100), 77 (37), 65 (42), 51 (10).

\section{References}

1. Plourde, G.L. Studies Towards the Diastereoselective Spiroannulation of Phenolic Derivatives. Tetrahedron Lett. 2002, 43, 3597-3599.

2. $\quad$ Plourde, G.L. Molbank 2003, M315-M322.

3. Plourde, G.L.; Fisher B.B. Synthesis of 6-Methoxy-1-oxaspiro[4,5]deca-6,9-diene-8-one. Molecules 2002, 7, 315-319. 
4. Plourde, G.L.; English, N.J. Diastereoselective Spiroannulation of Phenolic Substrates : Synthesis of ( \pm )-2-tert-Butyl-6-methoxy-1-oxaspiro[4,5]deca-6,9-diene-8-one. Molecules 2005, 10, 1335-1339.

5. MacDonald, G.; Alcaraz, L.; Lewis, N.J.; Taylor, R.J.K. Asymmetric Synthesis of the $m C_{7} N$ Core of the Manumycin Family: Preparation of (+)-MT35214 and a Formal Total Synthesis of (-)-Alisamycin. Tetrahedron Lett. 1998, 39, 5433-5436.

6. Alcaraz, L.; Macdonald, G.; Kapfer, I.; Lewis, N.J.; Taylor, R.J.K. The First Total Synthesis of a Member of the Manumycin Family of Antibiotics: Alisamycin. Tetrahedron Lett. 1996, 37, 6619-6622.

7. Alcaraz, L.; Taylor, R.J.K. The First Synthesis of the Streptomyces Derived Antibiotic U62162. Chem. Comm. 1998, 1157-1158.

8. Taylor, R.J.K.; Alcaraz, L.; Kapfer-Eyer, I.; Macdonald, G.; Wei, X.; Lewis, N. The Synthesis of Alisamycin, Nisamycin, LL-C10037 $\alpha$ and Novel Epoxyquinone Analogues of Manumycin A. Synthesis 1998, 775-790.

9. Wei, X.; Cronje Grove, J.J.; Taylor, R.J.K. The First Total Synthesis of ( \pm )-Colabomycin D. J. Chem. Soc. Perkin Trans. 1 1999, 1143-1145.

10. Wipf, P.; Coish, P.D.G. Total Synthesis of ( \pm )-Nisamycin. J. Org. Chem. 1999, 64, 5053-5061.

11. Alcaraz, L.; Macdonald, G.; Ragot, J.P.; Lewis, N.; Taylor, R.J.K. Manumycin A: Synthesis of the (+)-Enantiomer and Revision of Stereochemical Assignment. J. Org. Chem. 1998, 63, 35263527.

12. Alcaraz, L.; Macdonald, G.; Ragot, J.; Lewis, N.J.; Taylor, R.J.K. Synthetic Approaches to the Manumycin A, B and C Antibiotics: The First Total Synthesis of (+)-Manumycin A. Tetrahedron 1999, 55, 3707-3716.

13. Cronje Grove, J.J.; Wei, X.; Taylor, R.J.K. The First Total Synthesis of a Type I Manumycin Antibiotic, (+)-TMC-1A: The Total Synthesis of (-)-LL-C10037 $\beta$ and (+)-Manumycin B. Chem. Comm. 1999, 421-422.

14. Wipf, P.; Kim, Y. Stereoselective Synthesis of the Functionalized Spirocyclic Core of Aranorosin. J. Org. Chem. 1993, 58, 1649-1650.

15. Wipf, P.; Kim, Y.; Fritch, P.C. Total Synthesis and Structure Assignment of the Antitumor Antibiotic Aranorosin. J. Org. Chem. 1993, 58, 7195-7203.

16. McKillop, A.; McLaren, L.; Taylor, R.J.K.; Watson, R.J.; Lewis, N.J. The Total Synthesis of the Diepoxycyclohexanone Antibiotic Aranorosin and Novel Synthetic Analogues. J. Chem. Soc. Perkin Trans. 1 1996, 1385-1393.

17. Phoon, C.W.; Somanadhan, B.; Heng, S.C.H.; Ngo, A.; Ng, S.B.; Butler, M.S.; Buss, A.D.; Sim, M.M. Isolation and Total Synthesis of Gymnastatin N, a POLO-like Kinase 1 Active Constituent from the Fungus Arachniotus Punctatus. Tetrahedron 2004, 60, 11619-11628.

Sample availability: Available from the authors.

(c) 2007 by MDPI (http://www.mdpi.org). Reproduction is permitted for noncommercial purposes. 